\title{
A mathematical model of contagious bovine pleuropneumonia (CBPP) within-herd outbreaks for economic evaluation of local control strategies: an illustration from a mixed crop-livestock system in Ethiopian highlands
}

\author{
Matthieu LESNOFF ${ }^{\mathrm{a}, \mathrm{b} *}$, Géraud LAVAL ${ }^{\mathrm{a}}$, Pascal BONNET $^{\mathrm{a}, \mathrm{b}}$, \\ Asseguid WORKALEMAHU ${ }^{\mathrm{b}}$
}

\begin{abstract}
a Centre de coopération internationale en recherche agronomique pour le développement (CIRAD), Campus International de Baillarguet, TA 30/A, 34398 Montpellier Cedex 5, France

b Present address: International Livestock Research Institute (ILRI), PO Box 5689, Addis Ababa, Ethiopia
\end{abstract}

(Received 24 March 2003; accepted 3 June 2004)

\begin{abstract}
Contagious bovine pleuropneumonia (CBPP) is a respiratory disease of cattle caused by Mycoplasma mycoides subsp. mycoides small colony. CBPP is a major cause for concern in African countries (because of mortality, animal-production losses and cost of control). We present a simulation framework to compare economic efficiency of local (i.e., at the herd level) CBPP-control strategies (vaccination and antibiotic treatments). This framework was illustrated with data from an Ethiopian highlands cattle-smallholder system (Boji district, West Wellega Zone), where veterinary services recently reported CBPP cases and a research programme was set up to estimate the epidemiological parameters of infection spread. With the data considered (low CBPP virulence), antibiotics were the most efficient strategy. A sensitivity analysis should be carried out taking into account all uncertain parameters regarding economic values of costs and benefits, expected effectiveness of animal health interventions, animal production yields and epidemiological patterns of the disease. Our framework can help for decision making in CBPP management and health policy design at herd level. Moreover, any threshold analyses (e.g., value of vaccine cost for a benefit being nil) could easily be implemented.
\end{abstract}

contagious bovine pleuropneumonia / control strategies / economics / Markov model / Ethiopia

Résumé - Un modèle mathématique de la diffusion intratroupeau de la péripneumonie contagieuse bovine (PPCB) pour l'évaluation économique de stratégies locales de contrôle : une illustration dans un système mixte d'agriculture-élevage dans les hauts plateaux éthiopiens. La péripneumonie contagieuse bovine (PPCB) est une maladie respiratoire des bovins due à

* Corresponding author: m.lesnoff@ cgiar.org 
Mycoplasma mycoides subsp. mycoides small colony. La PPCB est un problème sanitaire majeur dans les pays africains (en raison de la mortalité, des pertes de production et du coût de contrôle). Nous présentons un modèle de simulation permettant de comparer l'efficience économique de stratégies de contrôle (vaccination et traitement antibiotique) au niveau du troupeau. Ce modèle a été illustré avec des données provenant d'un système mixte d'agriculture-élevage dans les hauts plateaux éthiopiens (district de Boji, zone du West Wellega), où des cas de PPCB ont été rapportés par les services vétérinaires et où un programme de recherche a été mis en oeuvre pour estimer les paramètres épidémiologiques de la PPCB. Avec les données considérées (faible virulence de la PPCB), les traitements antibiotiques ont été la stratégie la plus efficiente. Une analyse de sensibilité devra être mise en oeuvre pour prendre en compte l'incertitude des valeurs des paramètres économiques, de production animale et épidémiologiques. Notre modèle de simulation peut aider pour l'aide à la décision dans la gestion de la PPCB et la planification de programmes sanitaires. Le modèle permet aussi d'estimer les limites acceptables du coût des stratégies de contrôle au niveau du troupeau (par exemple le coût du vaccin engendrant un bénéfice nul).

péripneumonie contagieuse bovine / stratégies de contrôle / économie / modèle de Markov / Ethiopie

\section{INTRODUCTION}

Contagious bovine pleuropneumonia (CBPP) is a respiratory disease of cattle, caused by Mycoplasma mycoides subsp. mycoides small colony ( $\mathrm{MmmSC}$ ). CBPP is a list-A disease in the World Organisation for Animal Health (OIE) classification and a major concern in Africa (17 countries declared the disease in 2001) [24].

CBPP shows a large range in the degree of severity and signs [28]. Some cattle appear to be naturally resistant. Subclinical forms are frequent. Severe respiratory signs are the most-prominent features observed in the clinical cases. Contagion occurs through expectorations of infectious coughing cattle $[23,28]$.

In infected herds, losses are due to the mortality of clinical cases and to morbidity which affects production yields during the clinical phase (in relation to biological disorders and functional disabilities). Previous economic studies on CBPP were focused on vaccination plans (delivered through the government) at national (in south Sudan and Nigeria) or regional levels [25, 34]. They did not consider local strategies and the farmer perspective. Farmers can adopt, however, a private and individual management of CBPP, principally using antibiotic treatments of clinical cases [12, 16, 19]. Although commonly used in the field, antibiotics remain not officially recommended by OIE (they are suspected to increase the proportion of CBPP chronic carriers in herds [26] and to favour potential resistances of micro-organisms). Nevertheless, by reducing clinical phase duration, CBPP incidence and mortalities, antibiotic treatments might be an alternative strategy to vaccinations to control CBPP impact at the herd level [12].

The objective of this paper was to present a simulation framework to compare economic efficiencies of local (i.e. at the herd level) CBPP-control strategies. We illustrate this framework with data from an Ethiopian highlands cattle-smallholder system (Boji district, West Wellega Zone), where veterinary services reported CBPP cases [12] and a research programme was set up to estimate the epidemiological parameters of the infection spread $[14,19]$.

\section{MODEL FRAMEWORK}

\subsection{Within-herd CBPP-spread simulation}

A stochastic Markov-chain model was used to simulate CBPP spread after the herd infection, with or without animal health intervention. The model (see for details $[15,18]$ ) divided the herd into 4 infection-states (Fig. 1):

- $S$ : susceptible animals, 


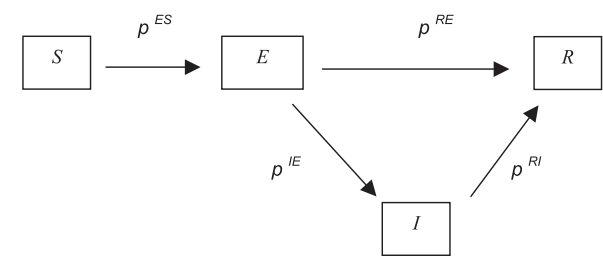

Figure 1. Schematic representation of the transitions between the different infection-states of the Markov-chain model. The model simulates the within-herd contagious bovine pleuropneumonia (CBPP) spread after the introduction of CBPP ( $S$ : susceptible animals, $E$ : incubating and not infectious animals, $I$ : infectious clinical cases, $R$ : recovered plus natural resistant animals). Parameters $\left\{p^{E S}, p^{I E}, p^{R E}, p^{R I}\right\}$ are the transition probabilities between the respective infection-states (Appendix 1). CBPP-specific mortality occurred only with clinical cases.

- $E$ : incubating animals (infected but not yet infectious),

- I: clinical cases (infectious),

- $R$ : recovered (immunised) plus naturally resistant animals (not infectious).

Although the involvement of CBPP chronic carriers in the long-term persistence of the disease in the cattle population has been suggested by several authors [20, 21, 28], the carriers' infectiousness (which remains unproven) and their role during the withinherd outbreak are negligible compared to clinical cases [33]. Therefore they were not represented in the model.

Let $x(t)$ be the herd vector at the beginning of week $t$. Each component of $x(t)$ represents the number of animals in a given infection-state. Following the herd infection, the Markov-chain model recurrently predicted the vectors $\{x(t)\}_{t=1 \ldots T}$ on a weekly basis. For each CBPP-control strategy we considered (vaccinations and antibiotic treatments) and the reference comparator (i.e., the situation with no health intervention), $n=$ 10,000 stochastic Monte Carlo replications of CBPP spread were undertaken. Natural death and offtake (i.e., slaughtering, sale or loan) occurred in each infection-state. CBPPspecific mortality occurred only with clinical cases. Transitions between infection-states, deaths and offtake were simulated from multinomial random generators (Appendix 1), which allows taking into account possible disease fade-outs, characteristics of small populations [3]. Removed animals (including those who have died from CBPP) were assumed to be replaced instantaneously through natural renewal and herd management (e.g., purchases, loans); the herd was in a demographic steady state.

The model-outputs of interest were the cumulative clinical incidence predicted in the herd during the outbreak $\left(\mathrm{CI}_{\mathrm{C}}\right.$ : total number of new clinical cases in the simulation) and the number of animals having died from CBPP. They were used to compare the effectiveness and the economic efficiency of CBPP-control strategies after financial conversions $\left(\mathrm{CI}_{\mathrm{C}}\right.$ and $\mathrm{CBPP}$-deaths were proportionally allocated to herd age composition groups).

The basic reproduction ratio $\left(R_{0}\right.$, Appen$\operatorname{dix} 2$ ) was also computed for each strategy. $R_{0}$ is the expected number of new infectious animals caused by a typical infected individual during its entire infectious period in a completely susceptible herd which is in a demographic steady state at the moment the infection is introduced $[1,8]$. In deterministic models, the disease can not persist below the threshold value $R_{0}=1$. In stochastic models, only small outbreaks can occur [7].

\subsection{The economic comparison}

We used gross margins [10] at the herd level (HGM; a difference between herd revenues and costs representing an annual benefit) for the comparison and acceptability criterion of CBPP-control strategies. Revenues were those of dairy $\left(\mathrm{R}_{\text {milk }}\right)$ and work (draught) $\left(\mathrm{R}_{\text {work }}\right)$ productions. Costs were the restocking of animals having died from $\mathrm{CBPP}\left(\mathrm{C}_{\text {restocking }}\right)$ and health interventions against $\mathrm{CBPP}\left(\mathrm{C}_{\mathrm{CBPP}}\right)$ :

$\mathrm{HGM}=\mathrm{R}_{\text {milk }}+\mathrm{R}_{\text {work }}-\mathrm{C}_{\text {restocking }}-\mathrm{C}_{\mathrm{CBPP}}$, 
(in which $\mathrm{C}_{\text {restocking }}$ and $\mathrm{C}_{\mathrm{CBPP}}$ were zero when there was no CBPP death or health intervention, respectively). Other revenues and costs in the herd were neglected or assumed independent of CBPP infection.

After herd infection, the annual revenues $\mathrm{R}_{\text {milk }}$ and $\mathrm{R}_{\text {work }}$ of clinical cases surviving to CBPP were reduced proportionally to the mean duration of the clinical phase. $R_{\text {milk }}$ and $\mathrm{R}_{\text {work }}$ of clinical cases dying of CBPP were reduced proportionally to the mean duration of the clinical phase prior to death.

HGM was computed for each CBPPspread Monte Carlo replication in each strategy and the reference comparator, and the empirical cumulative distributions were compared.

\section{ILLUSTRATION}

\subsection{The simulation scenario}

To illustrate our approach, we focused on a simplified scenario. We considered a CBPP-free herd in a high-risk environment (e.g., in an epidemic front or area); the herd was certain to have a contact with CBPP and the farmer was aware of that risk.

The herd infection corresponded to the introduction of one clinical case and the CBPP spread was simulated up to one year after the introduction. Possible external herd re-infections during the study-period (i.e., by importation of purchased-or-loaned infected cattle) were not considered. The 1-year horizon was in accordance with field epidemiological observations (outbreak durations $<1$ year if there is no herd re-infection) [4, 28] and preliminary mathematical simulation results. Moreover, this horizon complies with the agricultural cycle and, to our observations, and follows the rationale and perspective of local farmers in the Boji district when taking decisions.

In that risky situation, the farmer was assumed to use four alternative control-strategies. A first vaccine strategy (VACC3) was based on international recommendations, suggesting three successive vaccinations of the herd to reach a $100 \%$ protection rate with available vaccines (T1/44 and T1SR) [27]. A second vaccine strategy (VACC1) corresponded to a single vaccination, inducing protection rates from $40 \%$ to $60 \%$ [31]. The VACC1 protection rate was set to $50 \%$. VACC 3 and VACC 1 were preventative interventions: the herd infection was assumed to occur in the first month following the last vaccination. The vaccine protection was assumed to last one year [27]. Side-effects of vaccinations were neglected. The third strategy (ANT) consisted in curative antibiotic treatments of clinical cases in the infected herd. The treatment administration delay was set to 1 week after the occurrence of the first signs on the animal. To our knowledge, no published data (in experimental or field conditions) are available on antibiotic effectiveness, (e.g., the proportion of clinical recovering after treatment). We assumed this effectiveness was 100\%: all treated clinical cases recovered just after the treatment. Finally, the fourth strategy (VACC1-ANT) combined a single vaccination and antibiotic treatments of clinical cases occurring despite vaccination.

\subsection{Model inputs}

Model inputs came from production and epidemiological surveys conducted in the Boji district $[13,14,19]$ (when available) or from the literature. The farming system in Boji is representative of mixed crop-livestock systems commonly found in the East African highlands, where herds are sedentary and small $[9,11,14]$. Cattle are the cornerstone of the agricultural system: they provide milk, meat, and manure productions and animal draught power for crop cultivation.

To represent the Boji farming system, the herd was defined by the weaned animals (>9 months), kept at night in open temporary paddocks built around the farms [14]. Calves are more resistant to CBPP than adults $[6,28]$ and are locally kept away from the main herd. They were not considered. 
Table I. Epidemiological data used to estimate the parameter values of the within-herd contagious bovine pleuropneumonia (CBPP) spread Markov-chain model.

\begin{tabular}{lc}
\hline Parameter & Value \\
\hline $\begin{array}{l}\text { Proportion of infected animals in the herd } \\
1 \text { year after the infection (\%) }\end{array}$ & $35^{\mathrm{a}}$ \\
$\begin{array}{l}\text { Proportion of clinical cases within infected } \\
\text { animals (\%) }\end{array}$ & $39^{\mathrm{a}}$ \\
$\begin{array}{l}\text { Proportion of CBPP deaths within clinical } \\
\text { cases (\%) }\end{array}$ & $13^{\mathrm{a}}$ \\
$\begin{array}{l}\text { Mean duration of the incubation (week) } \\
\text { Mean duration of the clinical phase (week) }\end{array}$ & $6^{\mathrm{b}, \mathrm{c}}$ \\
$\begin{array}{l}\text { Proportion of natural resistant animals in the } \\
\text { herd (\%) }\end{array}$ & $10^{\mathrm{c}}$ \\
$\begin{array}{l}\text { Natural mortality risk (\% per year) } \\
\text { Offtake risk (\% per year) }\end{array}$ & $5^{\mathrm{a}}$ \\
\hline a 19$] ;$ & $15^{\mathrm{a}}$ \\
b [22, 28]; & \\
c [4].
\end{tabular}

The initial herd was composed of 15 animals.

Epidemiological data used to estimate the Markov chain model parameters are presented in Table I. They represented CBPPspread in an infected herd with no animal health intervention. These data corresponded to a relatively low CBPP virulence compared to outbreaks reported in pastoral systems $[4,28]$.

Data (except for direct cost due to CBPP) used to calculate HGM are presented in Table II. Dairy and work production revenues and cost of restocking were valuated at average market prices in the area.

In Ethiopia, the official CBPP-prevention strategy relies on vaccination. Ring vaccinations are generally delivered when CBPP outbreaks occur, if cases are reported and followed by action. Vaccines are produced by the public National Veterinary Institute (NVI). They are not directly sold to farmers at the present time and their manufacturing and distribution costs cannot be fully assessed from field data. In our study, the vaccine cost for the farmer was set to 2 Ethiopian birrs (ETB; 1 ETB $\approx 0.1$ Euro in 2003) per vaccinated animal. This represented a hypothetical situation in which vaccines are produced and delivered by the government with a cost-recovery policy (i.e., without a commercial benefit) (based on a cost-study by the Panafrican Rinderpest Campaign Programme in 1989-1996; [30]).

Table II. Production and economic data used to calculate the incremental herd gross margins $(\triangle \mathrm{HGM})$ for the contagious bovine pleuropneumonia (CBPP) control strategies evaluated in the study (except CBPP health intervention costs).

\begin{tabular}{|c|c|c|c|c|}
\hline & \multicolumn{2}{|c|}{$\begin{array}{c}\text { Subadults } \\
(9 \text { months } \leq \text { age }<4 \text { years })\end{array}$} & \multicolumn{2}{|c|}{$\begin{array}{c}\text { Adults } \\
(4 \text { years } \leq \text { age })\end{array}$} \\
\hline & Females & Males & Females & Males \\
\hline Herd age composition $(\%)^{\mathrm{a}}$ & 11 & 15 & 45 & 29 \\
\hline \multicolumn{5}{|c|}{ Revenues $\left(\right.$ ETB $^{\mathrm{b}}$ year $^{-1}$ and animal ${ }^{-1}$ ) } \\
\hline Work production (draught) ${ }^{\mathrm{c}}$ & 0 & 0 & 0 & 275 \\
\hline Milk production $^{\mathrm{c}}$ & 0 & 0 & 103 & 0 \\
\hline \multicolumn{5}{|l|}{ Costs $\left(\right.$ ETB animal $\left.{ }^{-1}\right)$} \\
\hline Animal restocking $\operatorname{cost}^{\mathrm{c}, \mathrm{d}}$ & 312 & 258 & 484 & 505 \\
\hline
\end{tabular}


Antibiotic treatment costs were estimated from field data (market price observations). The average cost of a complete sequence of treatments (following the manufacturer's recommended dosage) was 40 ETB per treated animal. It represented a treatment cost when delivery is private-based.

\subsection{Model results}

Mean- $\mathrm{CI}_{\mathrm{C}}$ was 2.1 animals when there was no intervention. The control strategies decreased mean- $\mathrm{CI}_{\mathrm{C}}$ below one animal (0.0, 0.7, 0.5 and 0.2 animal for VACC3, VACC1, ANT and VACC1-ANT, respectively), by decreasing the upper-tail percentiles of the $\mathrm{CI}_{\mathrm{C}}$ distribution and increasing the probability to not observe a clinical case after the herd infection (Fig. 2). $R_{O}$ values were 1.42 for the reference comparator (this last value was close to the threshold, indicating a low virulence) and $<1$ with the control $(0.0,0.7,0.4$ and 0.2 for VACC3, VACC1, ANT and VACC1-ANT, respectively).

All incremental HGM of the control strategies $\left(\mathrm{HGM}_{\text {strategy }}-\mathrm{HGM}_{\text {reference }}\right)$ were $>0$ on average. When comparing vaccination and treatment strategies, ANT (mean incremental HGM = 118 ETB) dominated VACC3 and VACC1 (mean incremental HGM $=18$ ETB and 55 ETB, respectively). The mixed strategy VACC1-ANT (incremental HGM = 96 ETB) dominated VACC1 but remained lower than ANT (despite the same magnitude).

Although the control generated positive mean benefits, the medians of the incremental HGM were negative (-101 ETB, -25 ETB, -13 ETB and -53 ETB for VACC3, VACC1, ANT and VACC1-ANT). The origin of this quite "counter-intuitive" pattern can be found by examining the empirical cumulative distributions (ecdf) of HGM (Fig. 3). The reference HGM-ecdf (no intervention) showed 3 successive plateaux (separated by marked vertical discrepancies), each corresponding to a different level of CBPP mortality in the simulations

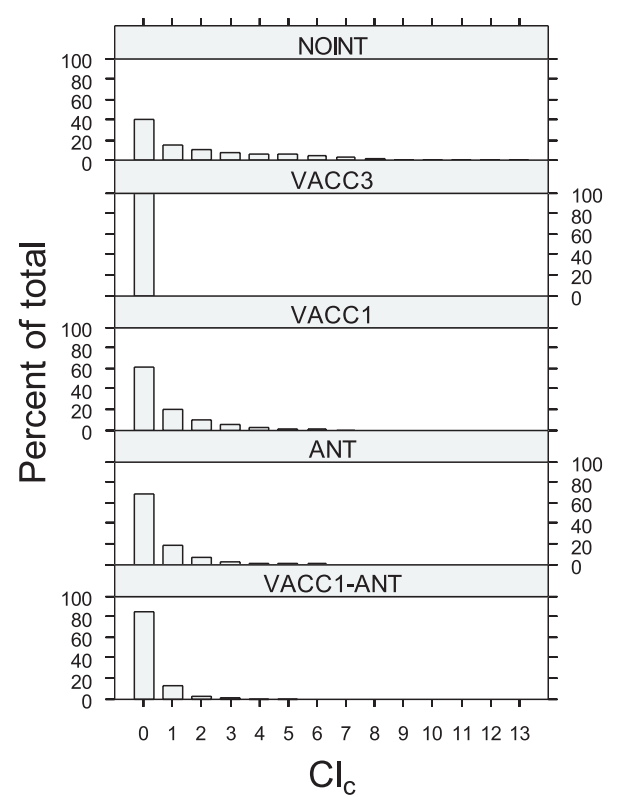

Figure 2. Empirical distribution of the cumulative clinical incidence $\left(\mathrm{CI}_{\mathrm{C}}\right.$ : total number of new clinical cases in the simulation) predicted from the within-herd contagious bovine pleuropneumonia (CBPP) spread Markov-chain model under the different considered CBPP-control strategies. (NOINT: no intervention, VACC 3: 3 successive vaccinations assuming a $100 \%$-protection rate, VACC1: 1 single vaccination assuming a $50 \%$-protection rate, ANT: antibiotic treatment of clinical cases assuming a 100\%-recovering rate, VACC1-ANT: mixed strategy combining 1 single vaccination and antibiotic treatment of clinical cases occurring despite vaccination).

$(0,1$ and 2 animals, respectively; higher mortalities represented less than $1 \%$ of the replications). This pattern indicates that the cost of restocking had a major influence on the HGM variations. The HGM-ecdf of control strategies were higher than the reference when one or more CBPP deaths occurred, but lower when there was no mortality. The latter situation corresponds to the highest plateau in the graph, which represented almost $70 \%$ of the replications in the reference and for which the financial losses represents almost the intervention 


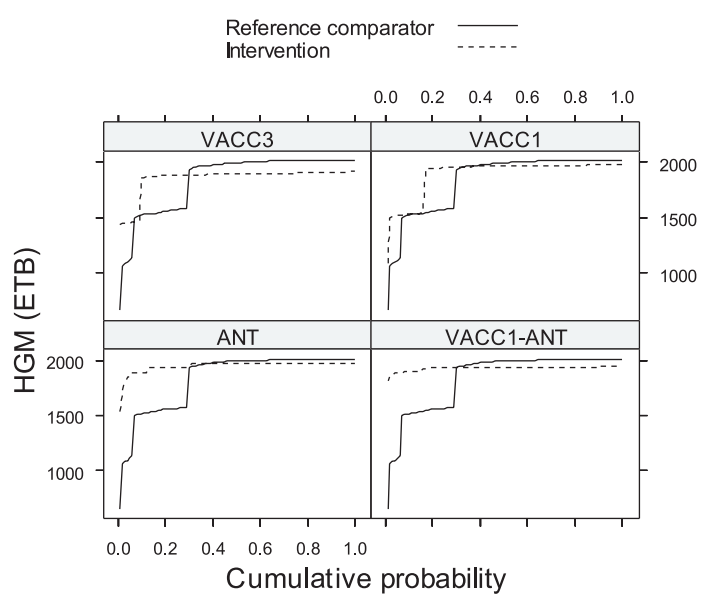

Figure 3. Empirical cumulative distribution of the herd gross margin (HGM) predicted from the within-herd contagious bovine pleuropneumonia (CBPP) spread Markov-chain model (after financial conversions) under the different considered CBPP-control strategies. (VACC3: 3 successive vaccinations assuming a 100\%-protection rate, VACC1: 1 single vaccination assuming a 50\%-protection rate, ANT: antibiotic treatment of clinical cases assuming a 100\%-recovering rate, VACC1ANT: mixed strategy combining 1 single vaccination and antibiotic treatment of clinical cases occurring despite vaccination). The reference comparator (no intervention against CBPP) distribution is plotted with a solid line in each cell of the graph. The incremental HGM $\left(\mathrm{HGM}_{\text {strategy }}-\mathrm{HGM}_{\text {reference }}\right)$ corresponds to the difference between the two plotted lines.

cost $\mathrm{C}_{\mathrm{CBPP}}$. As a consequence, all HGMpercentiles of order $>30 \%$ for control strategies were lower than the reference.

\section{DISCUSSION}

We provided a quantitative framework to evaluate and to rank CBPP control strategies with a farmer perspective. In our illustration (based on average parameter values observed in Ethiopian highlands), antibiotics were the most efficient strategy. This indicates that the use of antibiotic treatments could be reconsidered in African smallholder contexts, as also suggested by various authors (e.g. [29]). Nevertheless, the lack of scientific knowledge on the long-term biological effects of antibiotics remains a major limitation. If they favour the maintenance of a low level of infection in treated populations, it would be a counter-productive control measure when the objective is to eradicate the disease (i.e., when countries or regions have an economic comparative advantage in trading livestock in international markets).

For an appropriate use of the model towards final recommendations, a complete sensitivity analysis should be carried out taking into account all uncertain parameters. These parameters can be categorised into four dimensions: animal production yields and their economic evaluation, epidemiological patterns of the disease and health system characteristics. We only considered average yields and economic values estimated from our field and market observations and did not compute the efficiencies for any low-and-high hypotheses. The epidemiological pattern represented a low CBPP virulence, which highly influence the efficiency ranking. For example, other simulations (not detailed here) [17] showed that vaccination ranking is improved when CBPP virulence and the clinical incidence are higher, although antibiotics remained 
efficient. For strategies using antibiotic treatments, administration delays and underdosages (frequently observed in the field) are important parameters since they affect the utilisation effectiveness. Finally, the cost of health technologies (antibiotics and vaccines), which depends on national animal health policy (e.g., on the delivery channels and the governmental incentives), also determines the economic efficiencies of the different strategies [17].

The model framework presented allows various utilisations. The stochastic simulations provide two types of results: a strategy ranking based on mean outputs and the identification of efficiency plateaux and thresholds (within a given strategy) based on a comparison of empirical cumulative distributions. Ex ante simulations also represent a low cost alternative to ex post analysis of CBPP experimental trials to predict the impact of a variation of some key parameters (e.g., the treatment administration delay). The model also allows assessing the sensitivity of results to parameters that are not well documented. Therefore, it can guide the choice of further experimental and field research (e.g., trial effectiveness of antibiotics given different CBPP virulence). Within a decision-making process, it provides a user-friendly tool to determine threshold economic values in a given health system context (e.g., the maximum value of vaccine tariff for a benefit that is nil or, inversely, the maximum mortality acceptable given a vaccine tariff). All these issues could be considered with our model.

Nevertheless, the generalised utilisation of such a model framework as a decision helper is conditional to the availability of reliable data. At the present time and in developing countries, the scarcity of CBPP epidemiological data remains a major constraint [32]. This highlights the needs to define standardized methods to investigate CBPP outbreaks and to popularise them within the animal health system. The lack of knowledge on animal yields and on market prices is an additional limitation.
Finally, other models could be envisaged, particularly when the objective is to address long-term simulations and herd CBPP reinfection occurring along the study period due to the introduction of new animals. This would lead to more complex approaches as between-herd dynamics model.

\section{ACKNOWLEDGEMENTS}

We thank the Ministry of Agriculture of Ethiopia, the West Wellega Zonal Agricultural Office (Gimbi) and the Boji Woreda Agricultural Office (Bila) (including the staff of the Bila veterinary clinic) for their friendly co-operation to provide us the background for this study. We are warmly grateful to the field enumerators and the farmers of West Wellega Zone for their help in data collection. This work was funded by the Scientific Direction of CIRAD, through the grant "ATP 60/2000 - Modélisation d'une enzootie réémergente : cas de la péripneumonie contagieuse bovine en Éthiopie".

\section{Appendix 1. The CBPP-spread stochastic Markov-chain model.}

Let us consider a given week $t$. For mathematical convenience, death, offtake and renewal of animals were considered to occur at the end of the week, after the infection-state transitions; this has no importance in practice when the time-unit in simulations is low (as a day or a week).

Let $p^{i j}$ be the probability for an animal in infection state $i$ to transit in infection state $j$ during the week. The transitions between the infection-states (Fig. 1) were randomly generated as follows

- $S \rightarrow S$ or $E$ : multinomial M $\left(p^{S S}, p^{E S}\right)$,

- $E \rightarrow E, I$ or $R$ : multinomial $\mathrm{M}\left(p^{E E}, p^{I E}\right.$, $\left.p^{R E}\right)$,

- $I \rightarrow I$ or $R$ : multinomial $\mathrm{M}\left(p^{S S}, p^{E S}\right)$,

- $R \rightarrow R$ : with probability 1 .

Probability $p^{E S}$ was the probability of infection of susceptible animals during the week. It was defined following the 'pseudo-mass action law' [7]:

$$
p^{E S}=1-\exp (-\beta \times I(t)),
$$


where $\beta$ is the disease-transmission coefficient of clinical cases [3] and $I(t)$ the number of clinical cases present in the herd at the beginning of the week. Other transition probabilities were defined relative to the inverse of the mean duration of the infection-states [2,3]. Let $\phi$ be the proportion of clinical cases within the infected animals. Let also $\tau$ and $\mu$ be the mean durations in states $E$ and $I$, respectively. The transition probabilities from $E$ to $I$, from $E$ to $R$ and from $I$ to $R$ were $p^{I E}=\phi(1 / \tau), p^{R E}=(1-$ $\phi)(1 / \tau)$ and $p^{R I}=1 / \mu$, respectively.

Following the between-state transitions, the animals in states $S, E$ and $R$ were randomly distributed into survivals, deaths (basic mortality) or offtake from the multinomial distribution $\mathrm{M}\left(1-\pi_{\text {basic mortality }}\right.$ $\left.\pi_{\text {offtake }}, \pi_{\text {basic mortality }}, \pi_{\text {offtake }}\right)$. Animals in states $I$ were randomly distributed into survivals, deaths (basic mortality), deaths from CBPP (with probability $\alpha$ ) or offtake from the multinomial distribution $\mathrm{M}(1-$ $\pi_{\text {basic mortality }}-\alpha-\pi_{\text {offtake }}, \pi_{\text {basic mortality }}$, $\left.\alpha, \pi_{\text {offtake }}\right)$. Finally, removed animals were renewed into states $S$ or $R$ given the probability of natural resistance $p_{\text {res }}$ and the different control strategies.

In our case-study, the model parameter values were: $\beta=0.076$ week $^{-1}, \phi=0.39$, $\tau=6$ weeks, $\mu=4$ weeks, $\pi=0.0045, \alpha=$ 0.036 and $p_{\text {res }}=0.10$. All simulations were carried out with Matlab@)

\section{Appendix 2. Basic reproduction ratio $\boldsymbol{R}_{\boldsymbol{0}}$.}

The basic reproduction ratio $R_{0}$ corresponding to the within-herd CBPP-spread Markov-chain model was computed as follows (see [18] for demonstration):

$$
\begin{gathered}
R_{0}=\frac{(1-\pi-\alpha) p^{I E}}{1-(1-\pi)\left(1-p^{I E}-p^{R E}\right)} \\
\quad \times \frac{(1-\pi) \beta p_{r e s} N}{(1-\pi-\alpha) p^{R I}+(\pi+\alpha)},
\end{gathered}
$$

where $N$ was the herd size.

\section{REFERENCES}

[1] Anderson R.M., May R.M., Population biology of infectious diseases: Part I, Nature 280 (1979) 361-367.

[2] Anderson R.M., May R.M., Directly transmitted infectious diseases: control by vaccination, Science 215 (1982) 1053-1060.

[3] Anderson R.M., May R.M., Infectious diseases of humans. Dynamics and control, Oxford University Press, Oxford, 1991.

[4] Bygrave A.C., Moulton J.E., Shifrine M., Clinical, serological and pathological findings in an outbreak of contagious bovine pleuropneumonia, Bull. Epiz. Dis. Afr. 16 (1968) 21-46.

[5] CSA, Report on monthly average producers price of agricultural products in rural areas (Statistical Bulletin 251), Centre of Statistical Authority, Addis Ababa, 2001.

[6] Curasson G., Péripneumonie bovine, in: Traité de pathologie exotique vétérinaire et comparée - 2, Vigot-Frères, Paris VI, 1942, pp. 276-353.

[7] de Jong M.C.M., Mathematical modelling in veterinary epidemiology: why model building is important? Prev. Vet. Med. 25 (1995) 183193.

[8] de Jong M.C.M., Diekmann O., Heesterbeck J.A.P., The computation of R0 for discretetime epidemic models with dynamic heterogeneity, Math. Biosci. 119 (1994) 97-114.

[9] de Leeuw P.N., McDermott J.J., Lebbie S.H.B., Monitoring of livestock health and production in sub-Saharan Africa, Prev. Vet. Med. 25 (1995) 195-212.

[10] Dijkhuizen A.A., Morris R.S., Animal health economics. Principle and applications, University of Sidney, Sidney, 1997.

[11] Gryseels G., Anderson F.M., Research on farm and livestock productivity in the central Ethiopian highlands: initial results, 19771980. ILCA Research Report 4, International Livestock Center for Africa (ILCA), Addis Abeba, Ethiopia, 1983.

[12] Laval G., Analyse coût-bénéfice des méthodes de lutte contre la PPCB (péripneumonie contagieuse bovine) - Une application au niveau du troupeau dans le district de Boji, West Wellega (Ethiopie), Ph.D. Thesis, Université de Lyon I, Lyon, 2002.

[13] Laval G., Workalemahu A., Traditional Horro cattle production in Boji district, West Wellega (Ethiopia), Eth. J. Anim. Prod. 2 (2002) 97114. 
[14] Lesnoff M., Diedhiou M.L., Laval G., Bonnet P., Workalemahu A., Kifle D., Demographic parameters of domestic cattle in a contagiousbovine-pleuropneumonia infected area of Ethiopian highlands, Rev. Élev. Méd. Vét. Pays Trop. 55 (2002) 139-147.

[15] Lesnoff M., Thiaucourt F., Bonnet P., Bicout D., Balenghien T., Abdicho S., Laval G., Lancelot R., Un modèle conceptuel pour simuler la diffusion intra-troupeau de la péripneumonie contagieuse bovine, Rev. Elev. Méd. Vét. Pays Trop. 55 (2002) 253-257.

[16] Lesnoff M., Laval G., Abdicho S., Workalemahu A., Kifle D., Peyraud A., Bonnet P., Lancelot R., Thiaucourt F., Within-herd spread and clinical observations of contagious bovine pleuropneumonia in Ethiopian Highlands (Boji district, West Wellega): methodology and epidemiological results, in: 10th International symposium for veterinary epidemiology and economics, ISVEE, Viña del mar, Chile, 2003.

[17] Lesnoff M., Laval G., Bonnet P., Economic analysis of control strategies for contagious bovine pleuropneumonia (CBPP) outbreaks at herd level: a stochastic epidemiological model for smallholders in Ethiopian highlands, in: 10th International symposium for veterinary epidemiology and economics, ISVEE, Viña del mar, Chile, 2003.

[18] Lesnoff M., Laval G., Bonnet P., ChalvetMonfrey K., Lancelot R., Thiaucourt F., A mathematical model of the effects of chronic carriers on the within-herd spread of contagious bovine pleuropneumonia in an African mixed crop-livestock system, Prev. Vet. Med. 62 (2004) 101-117.

[19] Lesnoff M., Laval G., Bonnet P., Sintayehu A., Workalemahu A., Kifle D., Peyraud A., Lancelot R., Thiaucourt F., Within-herd spread and clinical observations of contagious bovine pleuropneumonia: a longitudinal survey in Ethiopian Highlands, Prev. Vet. Med. 64(2004) 27-40.

[20] Mahoney D.F., Epidemiological considerations in relation to the control of contagious bovine pleuropneumonia in north east Queensland, Aust. Vet. J. 30 (1954) 318-320.

[21] Martel J.L., Belli P., Perrin M., Dannacher G., Poumarat F., La péripneumonie contagieuse bovine, Rec. Méd. Vét. 161 (1985) 11051113.

[22] Masiga W.N., Domenech J., Windsor R.S., Manifestation and epidemiology of contagious bovine pleuropneumonia in Africa, Rev. Sci. Tech. Off. Int. Epiz. 15 (1996) 12831308.

[23] Nicholas R.A.J., Bashidurin J.B., Mycoplasma mycoides subsp. mycoides (small colony var- iant): the agent of contagious bovine pleuropneumonia and a member of the "Mycoplasma mycoides cluster", J. Comp. Biol. 113 (1995) $1-27$.

[24] OIE, Handistatus II, (2003) http://www.oie.int/hs2/.

[25] Oluokun S.B., Economic evaluation of animal disease control programmes in the developing countries: a case study on Nigeria, Bull. Off. Int. Epizoot. 92 (1980) 399-415.

[26] Provost A., Essai de traitement de la péripneumonie contagieuse des bovidés par la spyramicine, Cah. Méd. Vét. 43 (1974) 140-141.

[27] Provost A., Stratégies de prophylaxie et d'éradication de la péripneumonie contagieuse bovine avec ou sans vaccination, Rev. Sci. Tech. Off. Int. Epiz. 15 (1996) 1355-1371.

[28] Provost A., Perreau P., Bréard A., Goff C.L., Martel J.L., Cottew G.S., Contagious bovine pleuropneumonia, Rev. Sci. Tech. Off. Int. Epiz. 6 (1987) 625-679.

[29] Roeder P.L., Rweyemamu M., Could antibiotic therapy have a role in a strategy for combatting CBPP emergencies in Africa? in: Contagious bovine pleuropneumonia prevention and control strategies in Eastern and Southern Africa, Arusha, Tanzania, FAO-EMPRES/ OUA-IBAR, 1995, pp. 99-103.

[30] Tambi E.N., Maina O.W., Mukhebi A.W., Randolph T.F., Economic Impact Assessment of Rinderpest Control in Africa, Organisation of African Unity (OAU), Interafrican Bureau for Animal Resources (IBAR), Pan African Rinderpest Campaign (PARC), International Livestock Research Institute (ILRI), 1999.

[31] Thiaucourt F., Yaya A., Wesonga H.O., Huebschle O.J.B., Tuslane J.J., Provost A., Contagious bovine pleuropneumonia: a reassessment of the efficacy of vaccines used in Africa, Ann. NY Acad. Sci. 916(2000) 71-80.

[32] Windsor R.S., Changing patterns of contagious bovine pleuropneumonia, in: Report of second meeting of the FAO/OIE/OAU/IAEA consultative group on contagious bovine pleuropneumonia: reviving progressive control of CBPP in Africa, Rome, Italy, FAO/OIE/OAU/ IAEA, 2000, pp. 35-37.

[33] Windsor R.S., Masiga W.N., Investigation into the role of carrier animals in the spread of contagious bovine pleuropneumonia, Res. Vet. Sci. 23 (1977) 224-229.

[34] Zessin K.H., Carpenter T., Benefit-cost analysis of an epidemiologic approach to provision of veterinary service in the Sudan, Prev. Vet. Med. 3 (1985) 323-337. 